\title{
Processing of complementary food does not increase hair zinc levels and growth of infants in Kilosa district, rural Tanzania
}

\author{
Carl K. Lachat ${ }^{1,2}$, John H. Van Camp ${ }^{2}$, Peter S. Mamiro ${ }^{3}$, Francis Obuoro Wayua ${ }^{4}$, Anne S. Opsomer ${ }^{2}$, \\ Dominique A. Roberfroid ${ }^{1}$ and Patrick W. Kolsteren ${ }^{1,2} *$ \\ ${ }^{1}$ Nutrition and Child Health Unit, Department of Public Health, Prince Leopold Institute of Tropical Medicine, Nationalestraat \\ 155, B-2000 Antwerp, Belgium \\ ${ }^{2}$ Department of Food Safety and Quality, Faculty of Bioscience Engineering, Ghent University, Belgium \\ ${ }^{3}$ Department of Food Science and Nutrition, Sokoine University of Agriculture, Morogoro, Tanzania \\ ${ }^{4}$ National Arid Lands Research Centre, Kenya Agricultural Research Institute, Marsabit, Kenya
}

(Received 3 March 2005 - Revised 22 August 2005 - Accepted 28 August 2005)

\begin{abstract}
A community-based, randomized, placebo-controlled, double-blind trial was conducted from March 2001 to March 2002 in Kilosa, a rural district of Morogoro Region in Tanzania. One hundred and fifty-eight infants were selected randomly from lists of local Maternal and Child Health Care Centres and received either processed complementary food (PCF) or unprocessed complementary food (UPCF) from age 6 to 12 months. Processing increased $\mathrm{Zn}$ solubility and energy density of the porridge prepared from the complementary food (CF) as determined in vitro. Phytate:Zn molar ratio of the PCF and UPCF was $25 \cdot 8$ and $47 \cdot 5$, respectively. Under the study conditions, the processing of CF did not improve Zn status as measured by hair analysis. No significant correlations were found between hair $\mathrm{Zn}$ values and anthropometric measurements. Our findings suggest that processing alone of cerealbased CF may be insufficient to ensure an adequate supply of $\mathrm{Zn}$ to improve growth and $\mathrm{Zn}$ status of infants. Dietary modification to tackle $\mathrm{Zn}$ deficiencies in similar target groups may therefore only be successful when other Zn-rich foods such as meat and fish are included.
\end{abstract}

Complementary food: Zinc status: Infant growth: Tanzania

In developing countries, micronutrient deficiencies are widespread and manifest in the early stages of infant life. $\mathrm{Zn}$ deficiency is of particular importance (Salgueiro et al. 2002) and may result in retarded skeletal development and increased susceptibility to infections mediated via defects in the immune system (Food and Agriculture Organization/World Health Organization, 2002). The deficiency state of $\mathrm{Zn}$ is, however, difficult to diagnose because a reliable laboratory index to estimate $\mathrm{Zn}$ nutritional status is currently lacking (Wood, 2000; Hotz et al. 2003). Infants grow fairly well during the first months of life when they are exclusively breast-fed but, with the introduction of complementary foods (CF), a distinct plunge of mean weight-for-age or height-for-age is common. $\mathrm{CF}$ are typically cereal-based porridges with little vegetable or animal products (Michaelsen \& Friis, 1998; Davidsson, 2003). Both the high degree of phytates (myo-inositol hexaphosphate) present in whole-grain cereals and legumes and the poor quality in terms of the presence of minerals and vitamins lead to micronutrient deficiencies (Food and Agriculture Organization/World Health Organization, 2002). Phytate:Zn molar ratios $>15$ are believed to reduce $\mathrm{Zn}$ absorption levels to $15 \%$ (World Health Organization, 1996). Reduction of the phytate:Zn molar ratio is therefore a possible strategy to enhance Zn absorption (Manary et al. 2000). Hotz et al.
(2001) demonstrated how household preparation techniques can enhance in vitro $\mathrm{Zn}$ bioavailability of locally prepared maize-based $\mathrm{CF}$ in Malawi.

Interventions that target $\mathrm{Zn}$ deficiencies in developing countries are commonly based on food supplementation or fortification (World Health Organization, 2002). However, a food-based approach is generally believed to be a feasible and sustainable strategy to address $\mathrm{Zn}$ deficiencies (Gibson \& Ferguson, 1998).

The main hypothesis of the present trial was that an increased solubility of $\mathrm{Zn}$ through processing of $\mathrm{CF}$ would improve $\mathrm{Zn}$ status and growth of infants. The trial was part of a larger study that appraised the effects of locally prepared $\mathrm{CF}$ on growth and Fe status (Mamiro et al. 2004). Because low-cost, home-based strategies to alleviate $\mathrm{Zn}$ deficiencies are still not available in many developing countries, it was decided to document the effect of processing $\mathrm{CF}$ on $\mathrm{Zn}$ and growth in the present paper.

\section{Materials and methods}

Study area

The study was conducted in Kilosa district in Morogoro Region of the United Republic of Tanzania from March 2001 to March 2002. The region is located approximately

Abbreviations: CF, complementary food; LAZ, length-for-age Z-score; PCF, processed complementary food; UPCF, unprocessed complementary food; WAZ, weight-for-age Z-score; WLZ, weight-for-length Z-score.

* Corresponding author: Dr Patrick W. Kolsteren, fax + 3232476543 , email pkolsteren@itg.be 
$300 \mathrm{~km}$ west of Dar es Salaam and has a population of about 350000 inhabitants. Kilosa was chosen for the present trial because of its high prevalence of nutritional Fe deficiency, which is believed to coincide with $\mathrm{Zn}$ deficiency (Gibson et al. 2002; Lind et al. 2003). Specific data on Zn deficiencies for Kilosa district were not found.

\section{Study design}

The study was part of a larger, double-blind, randomized controlled trial in which the main investigator and the mothers had no knowledge of the type of food given to the infants. A CF quite similar to local traditional CF in Tanzania was formulated by the authors and produced locally. The effect of a processed complementary food (PCF) was then measured against that of an unprocessed complementary food (UPCF) which served as control.

The trial was approved by the ethics committees of both the Tanzanian Food and Nutrition Centre and Ghent University, Belgium. Parents of 364 infants aged 0 to 6 years gave verbal consent to participate and were randomized. Only three parents who were contacted refused to participate. Prior to enrolment, the health status of the infants was assessed by a medical doctor. Infants who were too ill to participate in the study were excluded and received medical care. Infants were continuously enrolled and entered the study when they were 6 months old and followed until the age of 12 months. Because of logistical difficulties, some time elapsed between initial randomization and enrolment. This resulted in the drop-out of fifty-five participants. Allocation to the treatment or control group was determined using a block randomization technique. Individuals were randomized on the basis of pre-established census lists. The code was not broken to the main investigator before the end of the data collection. Of the 309 infants who participated in the trial, 133 infants had enough hair to provide samples (Fig. 1). We subsequently computed whether this sample size allowed detection of meaningful differences in hair $\mathrm{Zn}$ levels between infants from the control and intervention group. Given the apparent large inter-subject variation in hair $\mathrm{Zn}$ content of the samples, a meaningful difference between the groups was arbitrarily defined as half the SD from the hair $\mathrm{Zn}$ analysis. Taking into account a significance level of 0.05 and the SD obtained from the hair analysis, this sample size showed a power of $88 \%$ to detect such difference and allows us to expose differences in change of mean weight-for-length Z-score (WLZ), weight-for-age Z-score (WAZ) and lengthfor-age Z-score (LAZ) of $0.54 \mathrm{sD}, 0.38 \mathrm{sD}$ and $0.37 \mathrm{sD}$, respectively. This power was considered sufficient to proceed with further computations. Calculations were done with Gpower version 2.0 (Erdfelder et al. 1996).

\section{Complementary food}

The CF was a mixture of finger millet (Eleusine corocana), kidney beans (Phaseolus vulgaris), peanuts (Arachis hypgoea) and mango (Mangifera indica). Processing involved roasting of peanuts to improve protein digestibility and destroy pathogenic micro-organisms (Brown et al. 1998; Gibson et al. 1998) and germination of finger millet and beans to increase solubility of $\mathrm{Zn}$ and Fe (Mbithi-Mwikya et al. 2002). The finger millet and beans were sorted, cleaned and soaked in pre-boiled water for 2 and $7 \mathrm{~h}$, respectively, and subsequently germinated for $48 \mathrm{~h}$ at $30^{\circ} \mathrm{C}$. The batch was then autoclaved and solar-dried for about $6 \mathrm{~h}$. Proliferation of pathogens such as Staphylococcus aureus and Bacillus cereus during germination was controlled with appropriate hazard analysis and critical control point procedures (Kimanya et al. 2003). Total phytate content of the $\mathrm{CF}$ was measured using colorimetric assays as described by Mbithi-Mwikya et al. (2002).

PCF and UPCF did not differ significantly in energy content $(P>0.05)$, which was 1731 (SD 11) and 1731 (SD 18) kJ/100 g $\mathrm{DM}$, respectively. The energy density of the porridge prepared with the PCF was $6100 \mathrm{~kJ} / \mathrm{l}$, compared with $1700 \mathrm{~kJ} / \mathrm{l}$ for the UPCF. The amounts of CF were such to provide at least $1151 \mathrm{~kJ} / \mathrm{d}$ for infants of $6-8$ months and $1883 \mathrm{~kJ} / \mathrm{d}$ for infants 9-11 months according to WHO guidelines (Brown et al. 1998) to meet the expected deficit in energy and protein. Since $30-45 \%$ of daily energy intake from fat is recommended for children less than 2 years old (Michaelsen \& Jorgensen, 1995), nurses advised to add 1-2 teaspoons (about $4 \mathrm{~g}$ ) of sunflower seed oil for each portion of the CF. Every two weeks, 1 and $1.6 \mathrm{~kg}$ of CF were provided for infants 6-8 and 9-11 months of age, respectively. On a daily basis, each child was supplied with 69 and $113 \mathrm{~g} \mathrm{CF}$ as DM. Mothers were instructed to prepare a fixed amount of this DM into porridge to give the child and to add 1-2 teaspoons of sunflower seed oil. A thorough description of the materials, methods and plan for hazard analysis and critical control point for the preparation of the CF has been given by the authors previously (Mamiro et al. 2004).

\section{Compliance and assessment of dietary intake}

The required amount of $\mathrm{CF}$ was distributed to the villages where it was stored in a securely closed cupboard to prevent spoilage. The mothers came to the health centre every two weeks to collect the CF. The nurses of the local health centre recorded every food collection using a list of the infants and demonstrated how to prepare the CF. In case of absence, the nurse ensured that a message was sent to the responsible mother or caregiver to collect her consignment on the same day. Nutrition officers from the health centres visited the mothers in their dwellings at least twice a week to verify that the CF was prepared and used correctly. They also made frequent surprise visits to observe compliance and solve any problems encountered. To estimate the amount of $\mathrm{CF}$ consumed by the infants, a $24 \mathrm{~h}$ dietary recall was carried out by a nutritionist assisted by a village health worker. Of the mothers of the 309 infants in the main trial, seventy-five were randomly selected in each intervention group, yielding seventy-one responses in the PCF and sixty-six in the UPCF group. The food consumed by the infants was estimated by the mothers and weighed using digital scales. FAO food composition tables were used to calculate macro- and micronutrient intakes (Food and Agriculture Organization, 1984).

\section{Zinc analysis}

Higher levels of soluble $\mathrm{Zn}$ in cereal-legume mixtures are associated with higher $\mathrm{Zn}$ uptake (Agte et al. 1997). In vitro solubility of $\mathrm{Zn}$ was therefore used in this study as a measure 


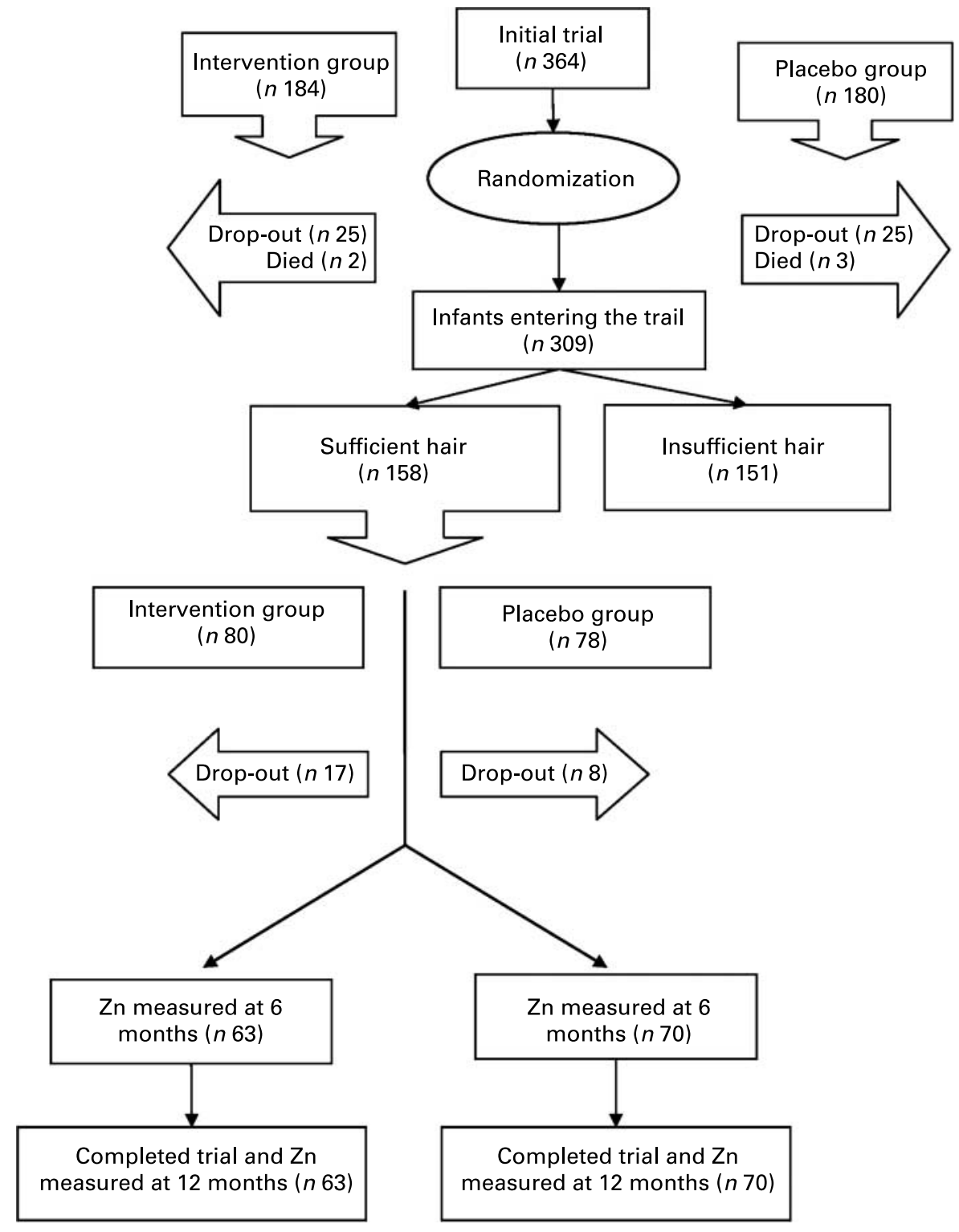

Fig. 1. Study design. Number of infants from the initial trial receiving processed (intervention group) or unprocessed complementary food (placebo group) and those providing hair samples for zinc analysis.

for $\mathrm{Zn}$ bioavailability in the CF. Extraction of $\mathrm{Zn}$ was carried out by wet-acid digestion using a nitric acid-perchloric acid mixture (5:1), 0.03- $\mathrm{M} \mathrm{HCl}$ and atomic absorption spectrophotometry as described by Kumar \& Chauhan (1993).

$\mathrm{Zn}$ status of infants was assessed using hair Zn. Because of the difficulty of drawing blood in our population (infants aged 6-12 months with high prevalence of anaemia), we wanted to limit the number of blood specimens and restrict those to finger pricks for $\mathrm{Hb}$. Biochemical indices of $\mathrm{Zn}$ status, such as serum and erythrocyte $\mathrm{Zn}$, or tests of immune competence were not attempted. Gibson et al. (1989) have proposed the cut-off value of hair $\mathrm{Zn}$ levels below $110 \mu \mathrm{g} / \mathrm{g}(1.68 \mu \mathrm{mol} / \mathrm{g})$ as an indicator of sub-optimal $\mathrm{Zn}$ status. Scalp hair was collected at baseline ( 6 months of age) and at the end of the trial (12 months of age) and analysed for $\mathrm{Zn}$ content. All measures were taken to avoid external sources of adventitious contaminations such as nits and lice during collection and preparation of the hair samples. The hair was cut with stainless steel scissors from the occipital region of the head as close to the scalp as possible. The samples were collected in small, clean, sterile plastic envelopes with a self-adhesive mechanism. The envelopes were coded, stored in a securely closed plastic bag and transported by airfreight to a laboratory in Belgium for analysis. Only the proximal $1-2 \mathrm{~cm}$ of the hair shaft was used since this part reflects recent trace element uptake by the follicles. Hair grows on average $1 \mathrm{~cm}$ per month (Wade \& Sinclair, 2002), so that the $\mathrm{Zn}$ content of hair $1-2 \mathrm{~cm}$ in length represents $\mathrm{Zn}$ uptake 2 to 3 months before sample collection (Dombovari \& Papp, 1998). Hence, in the present study, Zn concentrations in hair samples probably represent $\mathrm{Zn}$ status at age approximately 4 and 10 months, and not 6 and 12 months, respectively.

Before hair of the infants was analysed, the sample extraction methodology was optimized using extra hair samples 
from Belgian barber shops. Two methods of sample extraction were compared: dry ashing (Dombovari \& Papp, 1998) and wet digesting (Harrison et al. 1969), with Zn concentration determined by atomic absorption spectrophotometry. All preliminary analysis was carried out in duplicate. Mean $\mathrm{Zn}$ with wet digestion was 114.8 (SD 3.6) $\mu \mathrm{g} / \mathrm{g}$ dry hair and 108.3 (SD 5.9) $\mu \mathrm{g} / \mathrm{g}$ dry hair for dry ashing ( $n$ 10). Recovery was assessed for addition of $100 \mathrm{ml}$ and $200 \mathrm{ml} 0.015 \mathrm{mmol} / \mathrm{l}$ $\mathrm{Zn}\left(\mathrm{NO}_{3}\right)_{2}$. Wet digestion showed a comparatively larger recovery for $\mathrm{Zn}$ compared with dry ashing (106.0\% and $91.2 \%$, respectively). Mean differences for preliminary analysis were $14.8 \mu \mathrm{g} \mathrm{Zn/g}$ dry hair for the wet digestion ( $n$ 12) method and $15.7 \mu \mathrm{g} \mathrm{Zn/g}$ dry hair for the dry ashing method (n 11). Repeatability SD was 14.0 and $17 \cdot 6$, respectively. The wet digestion method was subsequently adopted as the reference method for the determination of $\mathrm{Zn}$ in the hair samples from Tanzania. Hair of 6- and 12-month-old infants was analysed concurrently. Because of the limited amount of hair that could be obtained from the infants, $\mathrm{Zn}$ analysis could not be performed in duplicate.

\section{Statistical analyses}

Data were entered in EPI-INFO (version 6.04d, 1996; Centers for Disease Control and Prevention, Atlanta, GA, USA/WHO, Geneva, Switzerland) and analysis was done using the Stata package (version 8.0; Stata Corp., College Station, TX, USA). Anthropometric indicators were computed using EPINUT according to 1977 growth reference data from the National Center for Health Statistics (Hyattsville, MD, USA). Descriptive statistics were computed for each variable to identify outliers and assess the normal distribution of continuous variables. Outliers were defined from the box plot as values more extreme than three interquartile ranges of the box. In the presence of outliers, a new variable was created excluding these values. However, in case of doubt, the data set was cross-checked with original data in the rosters. All tests were done first with the original variable, and then redone with the new variable to assess the influence of such outliers. Normal distribution of continuous variables was appraised by the Kolmogorov-Smirnov test. In the case of departure from normality, the variables were log-transformed (lnskew0 command in Stata) to apply statistics. Geometric means are presented in the tables where appropriate.

The $\alpha$ error was set at $5 \%$ and all tests were two-sided. A difference at 12 months between the two intervention groups was assessed for the primary outcome of mean $\mathrm{Zn}$ concentration in hair and anthropometric indicators, i.e. mean WLZ and mean LAZ. A standard $t$ test was used for continuous variables. The general trend in main outcomes between the beginning and the end of the trial was assessed by applying a paired $t$ test or a McNemar test for categorical variables.

\section{Results}

Subjects

In the main trial, the birth weight of the infants was 2.9 (SD 0.5 ) $\mathrm{kg}$ for the PCF group and 3.1 (SD 0.5) $\mathrm{kg}$ for the UPCF group and did not differ significantly between groups $(P=0 \cdot 06)$. Sex ratio was $1: 1$. The prevalence of wasting was significantly different between groups, while stunting, weight and length were equal in both groups. At baseline, infants with insufficient hair for analysis did not differ significantly in mean birth weight $(P=0 \cdot 15)$ and WLZ $(P=0.80)$, WAZ $(P=0.95)$ and LAZ $(P=0.80)$ from those who provided hair samples. Of the infants who provided hair samples, no differences in mean WLZ, WAZ and HAZ were found at baseline between infants receiving PCF and UPCF (Table 1).

\section{Complementary food}

Phytate content was reduced significantly by processing $(P=0.04)$ and was $660(\mathrm{SD} 20) \mathrm{mg} / 100 \mathrm{~g} \mathrm{DM}$ for PCF and 1150 (SD 30) $\mathrm{mg} / 100 \mathrm{~g}$ DM for UPCF. The processing of $\mathrm{CF}$ decreased the phytate: $\mathrm{Zn}$ molar ratio which indicates a successful improvement of absorption potential for $\mathrm{Zn}$ from the PCF compared with the UPCF. Table 2 describes the $\mathrm{Zn}$ content of the $\mathrm{CF}$ as obtained from analysis of twelve samples taken randomly every month from each CF production unit.

\section{Average dietary zinc supply}

Food consumption data from the $24 \mathrm{~h}$ recall showed no significant differences in daily intake of energy $(1752 v .1679 \mathrm{~kJ}$, $P=0.99)$ and protein $(17.9 v .18 .3 \mathrm{~g} / \mathrm{d}, P=0.68)$ from the $\mathrm{CF}$ between UPCF and PCF groups. The addition of oil increased the intake of energy from CF to 1943 and $1922 \mathrm{~kJ}(P=0.47)$ and for lipids to 31.3 v. $29.9 \mathrm{~g} / \mathrm{d}(P=0.24)$ for UPCF and $\mathrm{PCF}$, respectively. The CF alone contributed $>50 \%$ of the total daily energy intake and exceeded the age-specific WHO recommendations. The total number of meals of $\mathrm{CF}$ given to the child differed considerably between the groups, with 1-2 meals in the processed group v. 5-6 meals in the non-processed group. The overall average consumption of $\mathrm{CF}$ for both groups was $104 \mathrm{~g} \mathrm{DM} / \mathrm{d}$. Using soluble $\mathrm{Zn}$ as proxy for bioavailability and the total $\mathrm{Zn}$ content of the $\mathrm{CF}$, the total amount of available $\mathrm{Zn}$ received by the infants was thus: $\quad 2.53 \mathrm{mg} \quad \mathrm{Zn} / 100 \mathrm{~g} \times 104 \mathrm{~g} \quad \mathrm{CF} / \mathrm{d} \times 6.24 \%$ soluble $\mathrm{Zn}=0.164 \mathrm{mg} \mathrm{Zn} / \mathrm{d}$ for PCF and $2.4 \mathrm{mg} \mathrm{Zn} / 100 \mathrm{~g}$ $\mathrm{CF} \times 104 \mathrm{~g} \mathrm{CF} / \mathrm{d} \times 2.74 \%$ soluble $\mathrm{Zn}=0.0684 \mathrm{mg} \mathrm{Zn/d}$ for UPCF. Taking into account the $\mathrm{Zn}$ losses and allowing for growth, the $\mathrm{Zn}$ requirements for infants aged 6 to 12 months are estimated to be $2.8 \mathrm{mg} / \mathrm{d}$ (Brown et al. 1998). Our PCF met these requirements for $5.8 \%((0 \cdot 164 / 2 \cdot 8) \times 100)$ and UPCF for $2.4 \%((0 \cdot 068 / 2 \cdot 8) \times 100)$.

\section{Hair zinc levels}

Mean $\mathrm{Zn}$ hair concentration at baseline was 272.9 (SD 115.0) $\mu \mathrm{g} / \mathrm{g}$ for the control group and 253.4 (SD 100.0) $\mu \mathrm{g} / \mathrm{g}$ for the intervention group. At the end of the trial, these levels were 244.9 (SD 120.0) and 246.2 (SD 103.5) $\mu \mathrm{g} / \mathrm{g}$, respectively (Fig. 2). There was no significant difference $(P=0 \cdot 25)$ in mean hair $\mathrm{Zn}$ concentrations at baseline and at 12 months $(P=0.75)$ between infants receiving PCF and those receiving UPCF. The intervention did not produce a significant effect in both PCF $(P=0.33)$ and UPCF $(P=0.06)$ groups in terms of mean hair $\mathrm{Zn}$ concentration. Additionally, change in hair $\mathrm{Zn}$ at 6 and 12 months between PCF and UPCF was not significantly different $(P=0 \cdot 30)$. 
Table 2. Zinc content of the complementary foods (Mean values and standard deviations)

\begin{tabular}{lcccccc}
\hline & \multicolumn{4}{c}{ Complementary food } \\
\cline { 2 - 4 } & $\begin{array}{c}\text { Processed } \\
(n 12)^{*}\end{array}$ & & $\begin{array}{c}\text { Unprocessed } \\
(n \text { 12) }\end{array}$ & \\
\cline { 2 - 3 } Variable & Mean & SD & & Mean & SD & $P$ \\
\hline Zn (mg/100 g DM) & 2.53 & 0.09 & & 2.40 & 0.08 & 0.01 \\
Soluble Zn (\%) & 6.24 & 2.47 & & 2.74 & 1.49 & 0.003 \\
Phytate:Zn molar ratio & 25.8 & & 47.5 & & \\
\hline
\end{tabular}

*Twelve random samples of production batches.

At baseline, $7.9 \%$ of the infants receiving the PCF had hair $\mathrm{Zn}$ concentrations $<110 \mu \mathrm{g} / \mathrm{g}$ compared with $5.7 \%$ in the UPCF group. After the intervention, $6.3 \%$ of the infants receiving $\mathrm{PCF}$ and $7.1 \%$ receiving $\mathrm{UPCF}$ had hair $\mathrm{Zn}$ concentrations below the cut-off value. The percentages below the cut-off at baseline and end were not significantly different $(P=0 \cdot 60)$.

For all infants combined, infants with a hair $\mathrm{Zn}$ level below the cut-off value at baseline had an average increase in hair $\mathrm{Zn}$ of 159.0 (SD 127.8) $\mu \mathrm{g} / \mathrm{g}$ while the infants with hair $\mathrm{Zn}$ levels higher than the cut-off showed an average decrease of 31.0 (SD 103.1) $\mu \mathrm{g} / \mathrm{g}$. The difference of mean changes in hair $\mathrm{Zn}$ levels between these groups was highly significant $(P<0 \cdot 001)$.

\section{Effect of complementary food on growth}

At 12 months, WLZ, WAZ and LAZ were not significantly different between PCF and UPCF groups. Furthermore, the change in mean WLZ, WAZ and LAZ from 6 to 12 months was not significant (Table 1).

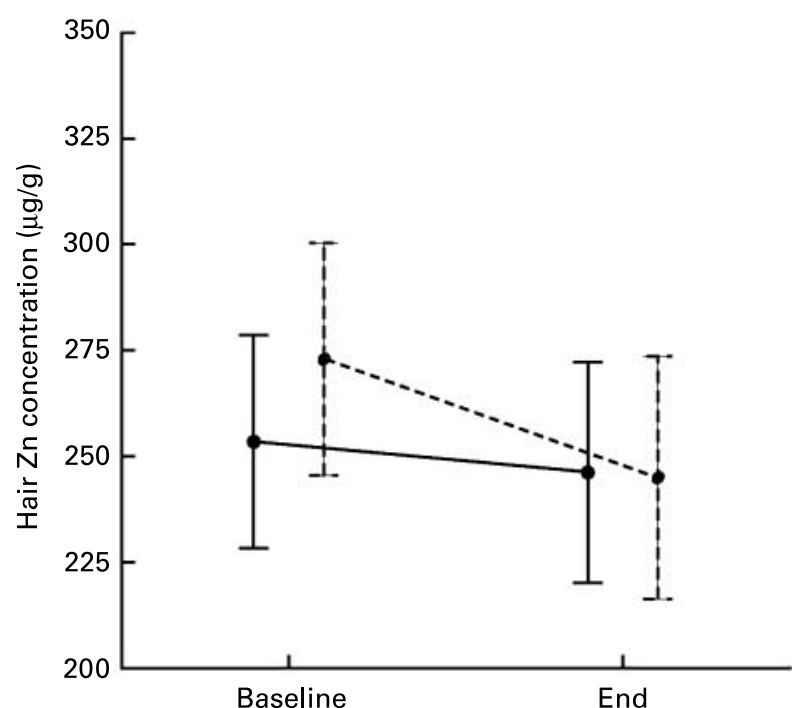

Fig. 2. Hair zinc concentration $(\mu \mathrm{g} / \mathrm{g})$ at baseline and end of the trial for infants who received processed complementary food (PCF; - - ) or unprocessed complementary food (UPCF; ----). Values are means with their $95 \%$ $\mathrm{Cl}$ shown by vertical bars for sixty-three subjects in the PCF group and seventy subjects in the UPCF group. 


\section{Discussion}

The present paper presents a secondary analysis of a trial investigating the effect of an improved processed $\mathrm{CF}$ on $\mathrm{Hb}$ status and growth of infants of aged 6 to 12 months. The results of the trial were reanalysed for their impact on $\mathrm{Zn}$ status and growth. Of the 309 infants in the main trial, 158 had sufficient hair for $\mathrm{Zn}$ analysis. Ex-post calculations showed that adequate detection power was obtained to show differences of at least $0.5 \mathrm{SD}$ in mean hair $\mathrm{Zn}$ concentration and WLZ, WAZ and LAZ between those receiving PCF and UPCF. No significant differences were found for the main indicators of nutritional status between infants with and without sufficient hair at baseline, suggesting that the analysis of a subgroup of the original sample was not a source of bias.

Although processing of a cereal-based CF resulted in higher energy density, higher levels of soluble $\mathrm{Zn}$ and lower phytate:Zn molar ratio, no significant expression of improved growth or $\mathrm{Zn}$ status was observed in the infants under the study conditions. Analysis of hair $\mathrm{Zn}$ levels showed no significant differences in hair $\mathrm{Zn}$ concentrations between the two groups post intervention, even though calculated intakes of the $\mathrm{Zn}$ were higher in the intervention group compared with the control group. Furthermore, regardless of food, infants in the present study with initial $\mathrm{Zn}$ deficiency as determined by cut-off levels of hair $\mathrm{Zn}$ managed to increase the $\mathrm{Zn}$ levels in hair while a decrease was observed for infants who were classified as not $\mathrm{Zn}$-deficient at baseline. This could be due to gastrointestinal regulatory mechanisms for $\mathrm{Zn}$ homeostasis as has been observed earlier in human subjects with prolonged Zn deficiency (Lee et al. 1993; King et al. 2000).

It is evident that the interpretation of the study results is hampered by the lack of a reliable index for $\mathrm{Zn}$ status in man and reference data for the study population. It is noteworthy that the hair $\mathrm{Zn}$ values in our study exhibited large variations. Similar values, in terms of absolute levels and variability, were also observed in Indonesian infants aged 5 months (Kolsteren et al. 1998) and Jamaican children aged 6-24 months (Meeks Garner et al. 1998). The large variations in the present study are unlikely to be attributable to the laboratory technique since the precision of the analyses as assessed by the recovery experiments was satisfactory and may be physiological. This study did not address seasonal influences, which may have a marked effect on hair Zn concentrations as described by Gibson et al. (1989). Infants in the present study were enrolled over a relatively long period of one year from March 2001 and March 2002, which arguably has levelled out seasonal variations.

Few infants had initial hair Zn levels below cut-off, which is consistent with Meeks Garner et al. (1998). In that Zn supplementation trial of stunted children aged 6 to 24 months, $13 \%$ of the Zn-supplemented group and $19 \%$ of the control group had hair $\mathrm{Zn}$ levels lower than $70 \mu \mathrm{g} / \mathrm{g}$. None of the infants in our study had hair Zn levels lower than this cutoff. Hair $\mathrm{Zn}$ content, however, may lack validity in cases of severe $\mathrm{Zn}$ deficiency (Gibson, 2004). The causes of stunting are complex and remain poorly understood. For children with impaired linear growth, Zn may not necessarily be the first limiting nutrient (Hautvast et al. 2000). Linear growth faltering may arise from multiple causes including the effects of chronic infections and prenatal and inter-generational effects of multiple micronutrient inadequacies in the diet, especially when the habitual diet is cereal-based. In these circumstances children are unlikely to show any improvement in linear growth in response to a $\mathrm{Zn}$ supplement unless $\mathrm{Zn}$ is the first limiting nutrient (Bates et al. 1993; Ferguson et al. 1993; Friis et al. 1997). Additionally, children in rural Tanzania are subjected to a multitude of infections. Environmental factors such as parasitic infections may have interfered with the effects of the intervention in terms of growth response. Mamiro et al. (2004) showed how nutritional status as measured by WLZ and LAZ deteriorated significantly during the intervention period for both the PCF and the UPCF groups. The elevated level of stunting amongst the infants in our study reflects an array of underlying deficiencies which may have masked the effect of the improved CF.

For ethical considerations, the mothers were asked to prepare a fixed amount of $\mathrm{CF}$, similar in both groups, every day, which resulted in equal amounts of energy intake between the groups. Energy density of the UPCF was more than three times lower than the PCF. Mothers had to administer the UPCF more than five times per day, compared to two times per day for the PCF, to obtain similar energy intakes. This may have introduced a bias in the study. Under less intense follow-up, the effect of the energy-dense CF may have been more pronounced (Mamiro et al. 2004).

Higher $\mathrm{Zn}$ content of the $\mathrm{CF}$ failed to improve growth significantly in terms of WLZ, LAZ and WAZ. This is in contrast to the results of a study by Umeta et al. (2000), who showed a significant improvement of linear growth, weight, WLZ, WAZ and LAZ in stunted Ethiopian infants. Hair Zn concentration was positively correlated with increased growth in the supplemented children. In Ethiopia, however, Zn was the primary growthlimiting nutrient in the infants (Gibson, 2000) and the trial used $10 \mathrm{mg} \mathrm{Zn}$ as $\mathrm{ZnSO}_{4}$ daily for $6 \mathrm{~d}$ per week during 6 months, which is considerably higher than in the present trial using dietary modification. Our findings are in line with the results of a study in Ghana, in which four groups of infants aged 6-12 months were fed for 6 months with different types of improved centrally processed CF. The study found no significant difference in $\mathrm{Zn}$ status measured by plasma Zn, WAZ and LAZ between 6 and 12 months in the infants who received the different $\mathrm{CF}$ (Lartey et al. 1999). Presumably, the levels of dietary intake in the present study are too low to produce any measurable effect in infants who are likely to be deficient in a number of nutrients.

Although processing decreased the phytate:Zn molar ratio considerably, the phytate content of the PCF still remained high. Even when $\mathrm{Zn}$ would have been $100 \%$, our cerealbased $\mathrm{CF}$ was unable to provide enough $\mathrm{Zn}$. Bearing in mind that refined diets low in cereals and rich in animal foods rarely surpass absorption levels of $50 \%$ (Hotz \& Brown, 2004), it is obvious that processing will remain inadequate under the study conditions. Surprisingly, the present study showed a decrease (not significant) in mean hair $\mathrm{Zn}$ levels after 6 months of intervention. This trend was also found in the control group. This observation seems to support our conclusions that the $\mathrm{CF}$ was unable to provide enough $\mathrm{Zn}$, regardless of the processing, and therefore suggests that homebased processing of cereal-based $\mathrm{CF}$ will not be able to improve growth and $\mathrm{Zn}$ status. Fortification of $\mathrm{CF}$ or $\mathrm{Zn}$ supplementation may be an alternative in this respect. Given the intricate relationship between micronutrient status and growth, however, a food-based approach has the considerable advan- 
tages of supplying a vast array of additional dietary compounds which are naturally present. Adding supplementary sources of Zn-rich foods, such as meat and fish, to $\mathrm{CF}$ seems to be indispensable to ensure an adequate and sustainable supply of sufficient micronutrients.

\section{Acknowledgements}

This study was funded by Nutrition Tiers Monde, the Steve Biko Project and the Flemish Inter-University Council (VLIR).

\section{References}

Agte VV, Gokhale MK \& Chiplonkar SA (1997) Effect of natural fermentation on in vitro zinc bioavailability in cereal-legume mixtures. Int J Food Sci Technol 32, 29-32.

Bates CJ, Evans PH, Dardenne M et al. (1993) A trial of zinc supplementation in young rural Gambian children. Br J Nutr 69, 243-255.

Brown K, Dewey K \& Allen L (eds) (1998) Complementary Feeding of Young Children in Developing Countries: A Review of Current Scientific Knowledge. Geneva: World Health Organization.

Davidsson L (2003) Approaches to improve iron bioavailability from complementary foods. J Nutr 133, Suppl., 1560S-1562S.

Dombovari J \& Papp L (1998) Comparison of sample preparation methods for elemental analysis of human hair. Microchem J 59, 187-193.

Erdfelder E, Faul F \& Buchner A (1996) Gpower. A general power analysis program. Behav Res Methods Instrum Comput 28, 1-11.

Ferguson E, Gibson R, Opare-obisaw C, Ounpuu S, Thompson LU \& Lehrfeld J (1993) The zinc nutriture of preschool children living in two African countries. J Nutr 123, 1487-1496.

Food and Agriculture Organization (1984) Cereals and grain products. In Food Composition Table for Use in Africa, pp. 98-101 [US Department of Health Education and Welfare, editor]. Rome: FAO.

Food and Agriculture Organization/World Health Organization (2002) Human Vitamin and Mineral Requirements. Report of a Joint WHO/ FAO Expert Consultation, Bangkok, Thailand. Rome: FAO.

Friis H, Ndhlovu P, Mdluza T, Kaondera K, Sandstrom B, Michaelsen K, Vennervald B \& Christensen N (1997) The impact of zinc supplementation on growth and body composition: a randomized, controlled trial among rural Zimbabwean schoolchildren. Eur J Clin Nutr 51, 38-45.

Gibson RS (2000) Zinc supplementation for infants. Lancet 355, 2008-2009.

Gibson RS (2004) Principles of Nutritional Assessment. New York: Oxford University Press.

Gibson RS \& Ferguson EL (1998) Nutrition intervention strategies to combat zinc deficiency in developing countries. Nutr Res Rev 11, $115-131$.

Gibson RS, Ferguson EF, Vanderkooy PDS \& MacDonald AC (1989) Seasonal variations in hair zinc concentrations in Canadian and African children. Sci Total Environ 84, 291-298.

Gibson RS, Ferguson EL \& Lehrfeld J (1998) Complementary foods for infant feeding in developing countries: their nutrient adequacy and improvement. Eur J Clin Nutr 52, 764-770.

Gibson RS, Heath A-LM \& Ferguson EL (2002) Risk of suboptimal iron and zinc nutriture among adolescent girls in Australia and New Zealand: causes, consequences, and solutions. Asia Pac J Clin Nutr 11, Suppl., S543-S552.

Harrison W, Yuracheck J \& Benson C (1969) The determination of trace elements in human hair by atomic absorption spectroscopy. Clin Chim Acta 23, 83-91.

Hautvast JLA, Tolboom JJM, Kafwembe EM, Musonda RM, Mwanakasale V, van Staveren WA, van't Hof MA, Sauerwein RW, Willems JL \& Monnens LAH (2000) Severe linear growth retardation in rural Zambian children: the influence of biological variables. Am J Clin Nutr 71, 550-559.
Hotz C \& Brown KH (2004) Assessment of the risk of zinc deficiency in populations and options for its control. International Zinc Nutrition Consultative Group. Food Nutr Bull 25, S91-S204.

Hotz C, Gibson R \& Temple T (2001) A home-based method to reduce phytate content and increase zinc bioavailability in maizebased complementary diets. Int J Food Sci Nutr 52, 133-142.

Hotz C, Lowe NM, Araya M \& Brown KH (2003) Assessment of the trace element status of individuals and populations: the example of zinc and copper. J Nutr 133, Suppl., 1563S-1568S.

Kimanya ME, Mamiro PRS, Van Camp J, Devlieghere F, Opsomer A, Kolsteren P \& Debevere J (2003) Growth of Staphylococcus aureus and Bacillus cereus during germination and drying of finger millet and kidney beans. Int J Food Sci Technol 38, 119-125.

King JC, Shames DM \& Woodhouse LR (2000) Zinc homeostasis in humans. J Nutr 130, Suppl., 1360S-1366S.

Kolsteren PW, Kardjati S, Traissac P \& Goyens P (1998) Hair zinc and copper in Indonesian infants. Asia Pac J Clin Nutr 7, 151-159.

Kumar A \& Chauhan BM (1993) Effects of phytic acid on protein digestibility (in-vitro) and $\mathrm{HCl}$-extractability of minerals in pearlmillet sprouts. Cereal Chem 70, 504-506.

Lartey A, Manu A, Brown KH, Peerson JM \& Dewey KG (1999) A randomized, community-based trial of the effects of improved, centrally processed complementary foods on growth and micronutrient status of Ghanaian infants from 6 to 12 mo of age. Am J Clin Nutr 70, 391-404.

Lee DY, Prasad AS, Hydrickadair C, Brewer G \& Johnson PE (1993) Homeostasis of zinc in marginal human zinc-deficiency - role of absorption and endogenous excretion of zinc. J Lab Clin Med 122, 549-556.

Lind T, Lonnerdal B, Stenlund H, Ismail D, Seswandhana R, Ekstrom EC \& Persson LA (2003) A community-based randomized controlled trial of iron and zinc supplementation in Indonesian infants: interactions between iron and zinc. Am J Clin Nutr 77, 883-890.

Mamiro PS, Kolsteren PW, Van Camp J, Roberfroid DA, Tatala S \& Opsomer AS (2004) Processed complementary food does not improve growth or hemoglobin status of rural Tanzanian infants from 612 months of age in Kilosa district, Tanzania. $J$ Nutr 134, 1084-1090.

Manary MJ, Hotz C, Krebs NF, Gibson RS, Westcott JE, Arnold T, Broadhead RL \& Hambidge KM (2000) Dietary phytate reduction improves zinc absorption in Malawian children recovering from tuberculosis but not in well children. J Nutr 130, 2959-2964.

Mbithi-Mwikya S, Van Camp J, Mamiro P, Ooghe W, Kolsteren PW \& Huyghebaert A (2002) Evaluation of the nutritional characteristics of a finger millet based complementary food. J Agric Food Chem 50, 3030-3036.

Meeks Garner J, Witter M \& Ramdath D (1998) Zinc supplementation: effects on growth and morbidity of undernourished Jamaican children. Eur J Clin Nutr 52, 34-39.

Michaelsen K \& Friis H (1998) Complementary feeding: a global perspective. Nutrition 14, 763-766.

Michaelsen KF \& Jorgensen MH (1995) Dietary-fat content and energy density during infancy and childhood - the effect on energy-intake and growth. Eur J Clin Nutr 49, 467-483.

Salgueiro MJ, Zubillaga MB, Lysionek AE, Caro RA, Weill R \& Boccio JR (2002) The role of zinc in the growth and development of children. Nutrition 18, 510-519.

Umeta M, West CE, Haidar J, Deurenberg P \& Hautvast JGAJ (2000) Zinc supplementation and stunted infants in Ethiopia: a randomised controlled trial. Lancet 355, 2021-2026.

Wade MS \& Sinclair RD (2002) Disorders of hair in infants and children other than alopecia. Clin Dermatol 20, 16-28.

Wood RJ (2000) Assessment of marginal zinc status in humans. $J$ Nutr 130, Suppl., 1350S-1354.

World Health Organization (1996) Trace Elements in Human Nutrition and Health. Geneva: WHO.

World Health Organization (2002) The World Health Report: Reducing Risks, Promoting Healthy Life. Geneva: WHO. 